\title{
Cross-Cultural Adaptation, Validity and Reliability of Malay Version Boston Carpal Tunnel Questionnaire
}

\author{
${ }^{1}$ Centre of Occupational Therapy Study, Faculty of Health Sciences, \\ Universiti Teknologi MARA, 42300, Malaysia \\ 2 Hand and Microsurgery Department, \\ Selayang Hospital, 68100, Malaysia
}

Anwar Abdullah¹, Ahmad Zamir Che Daud1', Akehsan Dahlan¹, Rashdeen Fazwi Muhammad Nawawi²

anw.abdullah@gmail.com,zamir_1225@yahoo.com, akehsan.dahlan@yahoo.com, rashdeenfazwi@netscape.net Tel: +601119277577

\begin{abstract}
This study aimed to assess the validity and reliability of the Malay version Boston Carpal Tunnel Questionnaire (M-BCTQ). A crosssectional study was used to generate the final version of M-BCTQ that was administered to 55 patients for psychometric testing. MBCTQ had excellent test-retest reliability with ICCs value 0.837 for Symptom Severity Scale (SSS) and 0.913 for Functional Status Scale (FSS). The Cronbach alpha coefficient for the internal consistencies was reported at 0.864 for SSS and 0.893 for the FSS. A strong correlation was found with the Malay version of Disability of Arm, Shoulder and Hand Questionnaire (MV-DASH) as Spearman correlation for construct validity was 0.791 for SSS and 0.831 for FSS.
\end{abstract}

Keywords: Carpal Tunnel Syndrome; Boston Carpal Tunnel Questionnaire; Reliability; Validity

eISSN: 2398-4287 @ 2019. The Authors. Published for AMER ABRA cE-Bs by e-International Publishing House, Ltd., UK. This is an open access article under the CC BYNC-ND license (http://creativecommons.org/licenses/by-nc-nd/4.0). Peer-review under responsibility of AMER (Association of Malaysian Environment-Behaviour Researchers), ABRA (Association of Behavioural Researchers on Asians) and CE-Bs (Centre for Environment-Behaviour Studies), Faculty of Architecture, Planning \& Surveying, Universiti Teknologi MARA, Malaysia. DOI: https://doi.org/10.21834/e-bpj.v4i12.1936

\subsection{Introduction}

Carpal Tunnel Syndrome (CTS) is a non-traumatic hand disorder that occurs from the entrapment of the median nerve that passes through the carpal tunnel in the wrist (Meyer et al., 2018)). Although the pathophysiology remains puzzling, CTS is related to the mechanical trauma and ischemic injury to the median nerve within the carpal canal (Werner \& Andary, 2002). The increase of pressure in the carpal tunnel resulting in the reduction of intraneural microcirculation with the breakdown of the blood-nerve barrier and formation of intraneural and extraneural oedema (Aboonq, 2015; MacDermid \& Doherty, 2004). CTS is commonly characterized by symptoms in the median nerve territory of the hand where the clinical presentations are intermittent paraesthesias and dysaesthesia that typically occurs at night and early in the morning (Hermiz \& Kallianen, 2017). The extent and severity of the median nerve's compression often impact the manifestation of remaining sign symptoms that include pain, disrupted sleeping pattern and reduced functional dexterity (Hall et al., 2013). The diagnostic criteria that used in the different setting have made the reported prevalence of CTS vary widely. The broad choices of measures in diagnosing CTS commonly involving the use of clinical presentation such as nocturnal wakening, a positive Phalen's test, a positive Tinel sign, sensory and motor deficits' test and electrophysiological and neurophysiological test (Graham, 2008). According to Padua et al. (2016), the diagnostic criteria results in better prevalence estimation than the use of electrophysiological measures. However, Mondelli, Giannini, \& Giacchi (2002) found that the incidence results differ when the clinical presentation is used

eISSN: 2398-4287 @ 2019. The Authors. Published for AMER ABRA cE-Bs by e-International Publishing House, Ltd., UK. This is an open access article under the CC BYNC-ND license (http://creativecommons.org/licenses/by-nc-nd/4.0). Peer-review under responsibility of AMER (Association of Malaysian Environment-Behaviour Researchers), ABRA (Association of Behavioural Researchers on Asians) and cE-Bs (Centre for Environment-Behaviour Studies), Faculty of Architecture, Planning \& Surveying, Universiti Teknologi MARA, Malaysia. DOI: https://doi.org/10.21834/e-bpj.v4i12.1936 
alone to describe the CTS. Accordingly, a better diagnosis should include the clinical criteria history from the patient's point of view, which is also able to guide the treatment outcomes and monitor progress. In this context, this can be achieved through the use of disease-specific outcome questionnaire that provides a more accurate assessment of complex evaluation on patient's discomfort.

Boston Carpal Tunnel Questionnaire (BCTQ) is the most preference patient-reported outcome measure (PROM) which explicitly assessing the CTS and has been most widely used in the last two decades (Rosales et al., 2016). BCTQ is a valid self-administered specific outcome to measure symptoms and functions of clients with CTS. It has been translated into different languages with high levels of reliability, validity and responsiveness (Multanen et al., 2019; Trybus et al., 2019; Hamzeh \& Alworikat, 2019; Bougea et al., 2017; Otero-Alvaro, Marin, \& Matas, 2016; Lue, Lu et al., 2014; Park et al., 2013; Imaeda et al., 2007; Sezgin et al., 2006;). BCTQ was validated in many languages; however, a Malay version of BCTQ is not available thus far. Hence, this study aimed to translate and evaluate the reliability and content-related validity Malay version BCTQ (M-BCTQ) for the use among Malay speaking people in Malaysia.

\subsection{Literature reviews}

Previously, the severity of symptoms of CTS was determined based on clinical symptoms and signs by a physician accompanied by neuromuscular studies. Recently, however, PROM is preferred than performance-based tests of hand functions (Yücel \& Seyithanoğlu, 2015). Usually, this is due to the performance-based tests that require specific training and types of equipment to attend, thus takes a longer time to complete. While the PROM is easy to conduct and clinically useful in determining the client's perception of their hand function and barriers in engaging daily living activities. PROM has better consideration to assess the level of patient's discomfort and impact on their social and employment status (Trybus et al., 2019). It can also determine the subjective aspect of a patient's condition, which is more reliable and administrable.

Several PROMs designed to assess symptoms, functional status and the treatment outcomes in CTS (Ollivere et al., 2009; Turner et al., 2010). Among the results, which often found in the literature in addition to BCTQ are the Michigan Hand Outcomes Questionnaire (MHQ) and Disabilities of Arm, Shoulder, and Hand Questionnaire (DASH) (Appleby, Neville-Smith, \& Parrott, 2009; Levine et al., 1993). $\mathrm{MHQ}$ measured the health status and functionality of clients with hand disorders (Waljee et al., 2011). It is a valid, reliable and responsive measure of hand and upper extremity conditions such as rheumatoid arthritis, distal radius fracture and CTS (Shauver \& Chung, 2009; Kotsis \& Chung, 2005; Chung et al., 1998). It has been translated into many languages (Ebrahimzadeh, Birjandinejad, \& Kachooei, 2015; Koziej et al., 2018; Meireles et al., 2014). DASH is an instrument that assessed the disability status and client's symptoms with hand and upper limbs conditions (Hudak, Amadio, \& Bombardier, 1996). DASH comprises of 30 items, which rated on a five-point Likert Scale. It has established excellent reliability and validity in the various language (Greenslade et al., 2004; Hobby, Watts, \& Elliott, 2005), including the MV-DASH by Al-Husuny et al., (2006). The MV-DASH has reported as having high internal consistency (Cronbach's alpha= $0.99)$, inter-rater reliability (ICC $=0.943)$, and good face validity.

BCTQ, the Levine scale (Levine et al. 1993), is a disease-specific instrument designed to assess symptoms severity and functional status of CTS's client. It comprised of two definite scales, 11-items in the Symptoms Severity Scale (SSS) and 8-items in the Functional Status Scale (FSS) which rated using a five-point rating scale. The total score is the sum of each item, and the higher score interprets the more significant disability. This PROM should be tailored and validated to the appropriate population and regional language and culture, especially in Malaysia, with a large proportion of about 32 million people. Malay is Malaysia's official language, as it is the primary means of communication commonly spoken by major ethnic groups in Malaysia, i.e. Malay, Chinese and Indian. Malay is the world's ninth most spoken language in the world, with over 200 million speakers (Baker \& Eversley, 2000). It can be accepted as one of the world's most widely spoken language. Given this situation, it is necessary to develop the Malay version of instrument specifically for the CTS patients to meet the needs of speakers in the fields of education and healthcare. The method of cross-cultural adaptation is necessary to be used to ensure the translated instrument is adapted culturally across different cultures of ethnicity in Malaysia. At the same time, the content reaches the equivalence as the original version of $\mathrm{BCTQ}$.

\subsection{Materials and methods}

\subsection{Participants}

Participants that recently diagnosed with idiopathic CTS in less than 3-months recruited from outpatients at the Hand and Microsurgery Unit of Selayang Hospital, Malaysia, from November 2018 to March 2019. The criteria for the diagnosis included typical clinical symptoms of CTS and results of physical examination and electrophysiological test. The typical symptoms, including nocturnal and associated paraesthesia of the hand, could be in one or both sides. However, only one hand with the worst symptoms was chosen for the study. Exclusion criteria were as follows: a patient who are under 18 years old, patient with the existence of other diseases that cause hand symptoms, including hypothyroidism, polyneuropathy, severe neuropathy of diabetes, history of hand trauma or surgery and recently confirm of pregnancy. A total sample of 65 patients and ten professional therapists were involved in this study. Of the 65 patients, ten patients have enrolled in the face validity study, along with ten professional therapists in content-related validity study. The remaining 55 patients who did not participate in the face validity study then participated in the reliability and validity study.

\subsection{Study design}


Three phases of the study were conducted, i.e., (1) translation and language validity, (2) face validity and content-related validity, and (3) test re-test reliability, internal consistency and construct validity. Translation and cross-cultural adaptation process were performed according to the guidelines by Sousa \& Rojjanasrirat (2011) and Beaton et al., (2000).

Phase 1: Translation and language validity

The original questionnaire was forward translated into Malay by two bilingual independent translators that generated two versions of M-BCTQ. Both versions were reviewed, and any differences were resolved by a bilingual occupational therapist that produced a single harmonized forward translation version. Then, the harmonized version was blindly back-translated to English by the third and fourth translators to provided two back-translated versions. A committee was formed to compare and analyze between the two back-translated versions, and between both back-translated versions and the original English version. A consensus was obtained by reviewing and resolving any discrepancies regarding conceptual and semantic equivalence to develop the prefinal version of $\mathrm{M}-\mathrm{BCTQ}$.

Phase 2: Face validity and content-related validity

A questionnaire was distributed to ten patients and ten expert reviewers from the professional therapists. The therapists were a native speaker of Malay language, which had at least three years of clinical experience in treating patients with CTS. Sample size with a minimum of 10 participants was recruited for each pretesting (Beaton et al., 2000; Sousa \& Rojjanasrirat, 2011). The patients were asked to give a response to ten statements of the questionnaire that comprises of ten areas based on their experience of using the prefinal version of M-BCTQ. For content validity, the same questionnaire was used along with three open-ended questions that asked the professional therapists' opinions and suggestion to further support the content equivalent and structure of the items in the prefinal version. The questionnaire using the 4-points Likert response scale measuring the levels of agreement were employed, i.e., 1: strongly disagree to 4: strongly agree. Content validity index at the item level (I-CVI) and the scale level (S-CVI/Ave) by Lynn (1986) was calculated as an empirical measurement analysis to validate the items and scale. The necessary modification was made to continue developing the prefinal version for psychometric testing.

Phase 3: Test re-test reliability, internal consistency and construct validity

A total of 55 patients with CTS were asked to administer the prefinal version of M-BCTQ for the psychometric testing. All issues and suggestions were addressed and resolved to produce the final version of $\mathrm{M}-\mathrm{BCTQ}$. The psychometric testing involves test re-test reliability on the same patients within 2-weeks, internal consistency and constructs validity by correlating between both scales in the final version of M-BCTQ and MV-DASH.

\subsection{Statistical analysis}

Test re-test reliability by using ICC was assessed by administrating to the same patients with the value above than 0.7 considered as having appropriate reliability (Streiner \& Norman, 2002). Internal consistency was measured by Cronbach's alpha coefficient with alpha value more than 0.7 considered as satisfactory, values more than 0.8 found as good, while values more than 0.9 considered as excellent correlation. Construct validity was assessed using Spearman's correlation coefficient by carrying out trials on the relationship between SSS and FSS of the final version of M-BCTQ and MVDASH with the correlation coefficient (Rs) value more than 0.7 indicates a strong correlation. All statistical tests were using IBM SPSS statistic 22.0 and P values less than 0.05 were considered to indicate statistical significance.

\subsection{Research ethics}

Ethical approvals to conduct this study were granted by the Research Ethics Committee, Universiti Teknologi MARA and the Medical Research and Ethics Committee, Ministry of Health, Malaysia (NMRR-18-970-40770(IIR)).

\subsection{Results}

\subsection{Face validity and content-related validity}

A group of 10 patients with typical signs and symptoms of CTS and ten bilingual OTs and PTs participated in the face and content validity assessment. All participants found that the prefinal version of the M-BCTQ was clear and presented no difficulty in answering the questions. 7 (70\%) of the expert reviewers were OTs while $3(30 \%)$ were PTs. Table 1 and Table 2 shows the demographics of the patient and expert reviewers, respectively, in the face and content validity's phase. Content validity index (CVI) used in this phase to analyze the themes selected for the process of face validity and content validity. Table 3 presented the CVI values from all participants in the face and content validity process. Number 1 indicates the favourable rating, while the unfavourable score has indicated by 0 . ICVI values of 0.78 (Lynn, 1986) or above and S-CVI/Ave values of 0.90 (Waltz, Strickland, \& Lenz, 2010) or above were the minimum acceptable indices to achieve. This study has found that S-CVI/Ave values were 0.93 for face validity and 0.90 for content validity, while all items were above 0.78 (I-CVI), indicating the M-BCTQ has a good face and content validity. None of the participants suggested that any issue should be included or omitted from the scale. Some experts suggested the response format should be placed in a table. All recommendations were taken for the final modification of the translated version according to the importance and relevancy. 
Table 1: Demographics of the patients.

\begin{tabular}{lc}
\hline Variables & $\mathrm{n}$ \\
\hline Gender, & \\
Women & 8 \\
Men & 2 \\
Age mean (SD) & $43.2(9.016)$ \\
Affected hand, $n(\%)$ & \\
Right & $3(30)$ \\
Left & $2(20)$ \\
Both & $5(50)$ \\
\hline
\end{tabular}

Table 2: Demographics of the expert reviewers.

\begin{tabular}{ll}
\hline Variables & $\mathrm{n}$ \\
\hline Gender, & \\
Women & 8 \\
Men & 2 \\
Age group (years) & \\
$20-29$ & 6 \\
$30-39$ & 4 \\
$40-49$ & 0 \\
Profession, & 7 \\
Occupational therapist & 3 \\
Physical therapist & \\
Academic qualification & 8 \\
Diploma & 2 \\
Degree & 0 \\
Master's degree & \\
Working experience (years) & 6 \\
$3-9$ & 4 \\
$10-19$ & 0 \\
$20-29$ & \\
\hline
\end{tabular}

Table 3: I-CVI and S-CVI/Ave values for the phase of face validity and content-related validity.

\begin{tabular}{lcc}
\hline Areas & Face validity $(\mathrm{n}=10) \mathrm{I}-\mathrm{CV} \mid$ & Content-related validity $(\mathrm{n}=10) \mathrm{I}-\mathrm{CV} \mid$ \\
\hline Communicate & 0.9 & 1 \\
Relevant & 0.8 & 1 \\
Easy to use & 1 & 1 \\
Comprehensive & 1 & 0.8 \\
Willing to repeat & 0.9 & 0.9 \\
Burden & 1 & 0.8 \\
Overlong & 0.8 & 0.8 \\
Embarrassing & 1 & 1 \\
Overcomplicated & 0.9 & 0.9 \\
Upsetting & 1 & 0.8 \\
\hline mean (S-CVI/Ave) & 0.93 & 0.90 \\
\hline
\end{tabular}

\subsection{Test-Retest, Internal Consistency, And Construct Validity}

A total of 55 consecutive patients with typical signs and symptoms of CTS confirmed by medical officers at the Selayang Hospital had agreed to participate and included in the psychometric testing. The mean age was 45.9 years (SD $=9.826)$, of whom $45(81.8 \%)$ were women, and $10(18.2 \%)$ were men. Symptoms of both hands were affected by CTS in $22(40 \%)$ patients followed by the right side in 21 $(38.2 \%)$ and the left hand in $12(21.8 \%)$. Most of the patients were Malays $37(67.3 \%)$ followed by Chinese $10(18.2 \%)$ and Indian 8 $(14.5 \%)$. All patients had no difficulties in answering the prefinal version of M-BCTQ and required 6-10 minutes to complete it. No ceiling and floor effects have found. Table 4 described the demographic characteristics of the patients in test-retest, internal consistency, and construct validity assessment.

Test-retest reliability assessed by using the ICCs that recorded from the same patients at a two-week interval for the first and second self-administration of the M-BCTQ. The average period between the two tests was $16.7 \pm 6.4$ days. Both scales of M-BCTQ had excellent test-retest reliability, with the values of ICCs were greater than 0.8 . The ICCs were 0.837 ( $95 \%$ confidence interval [CI], 0.736-0.902) for the SSS and 0.913 ( $95 \%$ confidence interval [Cl], 0.856-0.948) for the FSS. Table 5 presents the results of test-retest reliability. The Cronbach alpha coefficient for the internal consistencies was reported at 0.864 for SSS and 0.893 for the FSS. These Cronbach alpha values are considered good correlation as the value are greater than 0.8 . Detailed results of internal consistencies and the effect of item deletion on alpha values are presented in Table 6 and 7. The intercorrelation of both scales (FSS and SSS) in the final version of M$B C T Q$ demonstrated a strong correlation with correlation coefficient values of $0.716(p<0.001)$. A high correlation was reported between the scores of SSS and MV-DASH ( $r s=0.79, p<0.001$, two-tailed), that indicated satisfactory convergent validity the symptoms severity scale of both instruments. The score of FSS and MV-DASH also reported high correlation ( $r s=0.83, p<0.001$, two-tailed), indicating excellent convergent validity between both instruments.

Table 4: Demographics of the patients

\begin{tabular}{|c|c|}
\hline Variables & Values \\
\hline \multicolumn{2}{|l|}{ Gender, n (\%) } \\
\hline Women & $45(81.8)$ \\
\hline Men & $10(18.2)$ \\
\hline Age mean (SD) & $45.9(9.83)$ \\
\hline Affected hand, $\mathrm{n}(\%)$ & \\
\hline
\end{tabular}




\begin{tabular}{lc}
\hline Right & $21(38.2)$ \\
Left & $12(21.8)$ \\
Both & $22(40)$ \\
Employment status, $\mathrm{n}(\%)$ & \\
Employed & $41(74.5)$ \\
Unemployed & $8(14.5)$ \\
Retired & $6(11)$ \\
Races, $\mathrm{n}(\%)$ & \\
Malay & $37(67.3)$ \\
Chinese & $10(18.2)$ \\
Indian & $8(14.5)$ \\
Others & 0 \\
\hline
\end{tabular}

Table 5: Results on test-retest reliability, using intra-class correlation (ICC)

\begin{tabular}{lcc}
\hline Test-retest Reliability & Symptom Severity Scale & Functional Status Scale \\
\hline Mean (SD) for first measure & $2.43 \pm 0.58$ & $1.95 \pm 0.66$ \\
Mean (SD) for second measure & $2.32 \pm 0.58$ & $1.87 \pm 0.68$ \\
ICC (95\% CI) & $0.837(0.736-0.902)$ & $0.913(0.856-0.948)$ \\
Floor effects $(\%)$ & 0 & 0 \\
P value & $<0.001$ & $<0.001$
\end{tabular}

SD: standard deviation

Table 6: Mean values, correlations, and Cronbach $\alpha$ coefficient for SSS.

\begin{tabular}{|c|c|c|c|c|c|c|c|}
\hline & Mean & Std. deviation & $\begin{array}{l}\text { Scale Mean if } \\
\text { Item Deleted }\end{array}$ & $\begin{array}{l}\text { Scale Variance if } \\
\text { Item Deleted }\end{array}$ & $\begin{array}{l}\text { Corrected Item- } \\
\text { Total Correlation }\end{array}$ & $\begin{array}{l}\text { Cronbach's Alpha } \\
\text { if Item Deleted }\end{array}$ & $\begin{array}{l}\text { Cronbach's } \\
\text { Alpha }\end{array}$ \\
\hline SSS & & & & & & & 0.864 \\
\hline Q1 & 2.53 & 0.81 & 24.218 & 34.914 & 0.573 & 0.852 & \\
\hline Q2 & 2.31 & 0.90 & 24.436 & 35.732 & 0.422 & 0.862 & \\
\hline Q3 & 2.44 & 0.74 & 24.309 & 35.403 & 0.583 & 0.852 & \\
\hline Q4 & 2.64 & 1.19 & 24.109 & 30.173 & 0.725 & 0.839 & \\
\hline Q5 & 2.47 & 1.14 & 24.273 & 30.869 & 0.707 & 0.840 & \\
\hline Q6 & 2.62 & 0.87 & 24.127 & 35.002 & 0.516 & 0.855 & \\
\hline Q7 & 2.18 & 0.79 & 24.564 & 35.436 & 0.529 & 0.855 & \\
\hline Q8 & 2.55 & 0.77 & 24.200 & 36.089 & 0.479 & 0.858 & \\
\hline Q9 & 2.51 & 0.69 & 24.236 & 35.813 & 0.580 & 0.852 & \\
\hline Q10 & 2.71 & 1.01 & 24.036 & 35.110 & 0.412 & 0.865 & \\
\hline Q11 & 1.80 & 0.78 & 24.946 & 34.015 & 0.711 & 0.843 & \\
\hline
\end{tabular}

Table 7: Mean values, correlations, and Cronbach alpha coefficient for FSS.

\begin{tabular}{ccccccc}
\hline & Mean & Std. deviation & $\begin{array}{c}\text { Scale Mean if Item Scale Variance if } \\
\text { Deleted }\end{array}$ & $\begin{array}{c}\text { Corrected Item- } \\
\text { Item Deleted } \\
\text { Total Correlation }\end{array}$ & $\begin{array}{c}\text { Cronbach's Alpha } \\
\text { if Item Deleted }\end{array}$ & $\begin{array}{c}\text { Cronbach's } \\
\text { Alpha }\end{array}$ \\
\hline FSS & & & & & & \\
0.893 \\
Q1 & 1.67 & 0.69 & 13.891 & 23.247 & 0.558 & 0.889 \\
Q2 & 1.75 & 0.95 & 13.818 & 20.263 & 0.740 & 0.872 \\
Q3 & 1.71 & 0.71 & 13.855 & 21.756 & 0.785 & 0.871 \\
Q4 & 1.89 & 0.76 & 13.673 & 21.743 & 0.725 & 0.875 \\
Q5 & 2.07 & 1.03 & 13.491 & 19.884 & 0.707 & 0.876 \\
Q6 & 2.25 & 0.90 & 13.309 & 21.625 & 0.596 & 0.887 \\
Q7 & 2.53 & 0.98 & 13.036 & 20.702 & 0.653 & 0.882 \\
Q8 & 1.69 & 0.84 & 13.873 & 21.632 & 0.661 & 0.880 \\
\hline
\end{tabular}

Table 8: Correlation between M-BCTQ and MV-DASH.

\begin{tabular}{lc}
\hline M-BCTQ $(n=55)$ & MVDASH \\
\hline Mean (SD) & $28.30 \pm 17.12$ \\
Spearman's correlation coefficient with SSS & 0.791 \\
Spearman's correlation coefficient with FSS & 0.831 \\
\hline
\end{tabular}

\subsection{Discussion}

BCTQ was developed for use in a heterogeneous sample of patients of a wide age range with CTS (Levine et al., 1993). This evaluation tool has values that assessing the subjective discomfort and functional capacity of the hand in quick and easy in comparison to other outcome measures. This current study has introduced the M-BCTQ according to the guideline that designed for use in cross-cultural health care research. This guideline was to ensure the M-BCTQ is cross-culturally validated and reliable for the Malaysian population. No changes were made base on the original version. The results of the psychometric testing of $\mathrm{M}-\mathrm{BCTQ}$ were comparable to other validation studies. The empirical measurement analysis by using $\mathrm{CVI}$ in content validity has verified content equivalence and structure format of items and scale of $\mathrm{M}-\mathrm{BCTQ}$ as good as the original version.

The majority of patients in the current study were women $(81.8 \%)$, which women are more likely than men to encounter CTS (Burton et al., 2018). About $22 \%$ of patients had bilateral CTS, which affects their abilities to perform daily living tasks thoroughly. While approximately $41 \%$ of patients still working in different industries, which require their hands to sustain their productivity. The social 
consequences for the patient may lead to lost days of work, job changes and high healthcare cost as the symptoms encountered (Feuerstein et al., 1998). Participation of various races of the patient from Malay, Chinese and Indian, as Malaysian's native speakers, represented the significant ethnicity in Malaysia. It is essential and valuable in the evaluation of the translated scale to ensure its usefulness according to Malaysian's context and perspectives. A systematic method of forward and backward translation by translators on the M-BCTQ has a high-quality translation. Involvement of experts' participation among OTs and PTs for their agreement on usability and accuracy of items in both M-BCTQ's scale has assured the content-related validity were firmly retained.

The present study demonstrated high levels of reliability and validity of M-BCTQ in patients with CTS. The ICC was calculated for the test re-test reliability for the present study. It is more accurate, adequate and unbiased for an estimate of re-test correlation for any sample size (Hopkins, 2000). The value of ICC of both scales in M-BCTQ was higher than 0.8 that testify to excellent test-retest reliability. The excellent value of ICC for SSS showing comparable results with previously validated version, while, the FSS value was as high up to 0.9, similarly with Arabic and Spanish translation (Hamzeh \& Alworikat, 2019; Otero-Alvaro et al., 2016). Although the agreement was reached between the first and second measures within the 2-weeks interval as compared to previous studies (Ebrahimzadeh et al., 2015; Lue et al., 2014) which were shorter (within a week), ICC in the current study shows excellent test reliability. Thus, the translated questionnaire traded as comprehensible and reliable as the version contained in the other languages.

The Cronbach alpha coefficient of M-BCTQ in both scales demonstrated good internal consistency. It was very similar to the Arabic and Persian version (Hamzeh \& Alworikat, 2019; Hassankhani et al., 2018), as well as to previous validation studies. Only the Polish (Trybus et al., 2019) and Korean (Park et al., 2013) version demonstrated excellent internal consistency for both scales with the Cronbach alpha coefficient value more than 0.9 . There is no significant effect on the Cronbach alpha values for the individual item deletion. Thus, all items in the M-BCTQ were in the same domain and correlated with each other.

M-BCTQ was compared with MV-DASH to evaluate the convergent validity as per the previous study in other languages (Hamzeh \& Alworikat, 2019; Trybus et al., 2019; Lue et al., 2014; Park et al., 2013; Imaeda et al., 2007). The current study found a strong correlation in both scales of M-BCTQ and MV-DASH that showed good validity, but, only the Korean version has shown a better relationship than the current study. MV-DASH is a region-specific outcome measure designed to evaluate the entire upper limb impairment and symptoms, highly responsive to CTS patients (Hudak et al., 1996). In many studies, the MV-DASH's 30-item disability/symptom scale has been shown to have the same domain as in the M-BCTQ, making it the critical basis for the validation process of the new translated version. Previous studies were also conducted to evaluate the validity of their translation version BCTQ with other outcome measurements such as the more general questionnaire of Short Form 36 (SF-36) (Sezgin et al., 2006) and with the more specific questionnaire of the Michigan Hand Outcomes Questionnaire (MHQ) (Trybus et al., 2019), found deficient and negative correlation, respectively, to reflect different domains.

\subsection{Conclusion and recommendation}

Limitation of the current study includes a small sample size from a single medical centre. Multicenter studies involving non-surgical and surgically treated patients were planned to enhance generalization. Secondly, the responsiveness of the M-BCTQ was not done to complete the process of validation. Future study should take higher sample sizes into account and include the responsiveness process to the particular intervention and time for further testing of M-BCTQ.

Findings from this current study that were derived through the use of sufficient statistical analysis have verified that the M-BCTQ has excellent reliability with the ICCs value of 0.837 for the SSS and 0.913 for the FSS. At the same time, the Cronbach alpha coefficient was reported at 0.864 for SSS and 0.893 for the FSS. A strong correlation between both subscales of M-BCTQ and the MV-DASH established the concurrent validity. Thus, the M-BCTQ can be widely used as an evaluation tool for patients with CTS as a primary outcomes measure of clinical and post-operative treatment for Malay speaking population in Malaysia. The applicability of this M-BCTQ will support the evidence-based practice in the development of the framework for healthcare according to Malaysian context and perspectives.

\section{Acknowledgement}

The authors would like to thank committee members and Institut Terjemahan Buku Malaysia for technical assistance with the translation. Thanks to the Physical Therapist and Occupational Therapist in the Microsurgery and Hand Unit of Selayang Hospital, Madam Julia and Madam Raimi Sakinah for the help with data collection. All the Physical Therapists and Occupational Therapists in the Rehabilitation Unit and all the hand therapy patients who participated in this study. This study was funded under BESTARI grant by UiTM - (600IRMI/DANA 5/3/BESTARI (064/2017).

\section{References}

Aboonq, M. S. (2015). Pathophysiology of carpal tunnel syndrome. Neurosciences, 20(1), 4-9.

Al-Husuny, A., Rampal, L., Arumugam, M., Rahman, H. A., \& Zakaria, J. (2006). Validation of a Malay Version of Disability of Arm, Shoulder and Hand Questionnaire (MVDASH). https://doi.org/10.5014/ajot.2011.000794

Appleby, M. A., Neville-Smith, M., \& Parrott, M. W. (2009). Functional outcomes post carpal tunnel release: a modified replication of a previous study. Journal of Hand 
Therapy, 22(3), 240-248.

Baker, P., \& Eversley, J. (2000). Multilingual Capital: The languages of London's schoolchildren and their relevance to economic, social and educational policies. Battlebridge publications.

Beaton, D. E., Bombardier, C., Guillemin, F., \& Ferraz, M. B. (2000). Guidelines for the process of Cross Cultural adaptation of Self Report mesures. Spine, 25(24), 3186-3191. https://doi.org/10.1097/00007632-200012150-00014

Bougea, A., Zambelis, T., Voskou, P., Katsika, P. Z., Tzavara, C., Kokotis, P., \& Karandreas, N. (2017). Reliability and Validation of the Greek Version of the Boston Carpal Tunnel Questionnaire. Hand, 00(0), 1-7. https://doi.org/10.1177/1558944717725379

Burton, C. L., Chen, Y., Chesterton, L. S., \& Windt, D. A. Van Der. (2018). Trends in the prevalence, incidence and surgical management of carpal tunnel syndrome between 1993 and 2013 : an observational analysis of UK primary care records. BMJ Open, 8, 1-11. https://doi.org/10.1136/bmjopen-2017-020166

Chung, K. C., Pillsbury, M. S., Walters, M. R., \& Hayward, R. A. (1998). Reliability and validity testing of the Michigan Hand Outcomes Questionnaire. Journal of Hand Surgery, 23(4), 575-587.

Ebrahimzadeh, M.H., Birjandinejad, A., \& Kachooei, A. R. (2015). Cross-cultural adaptation, validation, and reliability of the Michigan Hand Outcomes Questionnaire among Persian population. Hand Surg, 20, 25-31.

Ebrahimzadeh, Mohammad H, Moradi, A., Vahedi, E., Kachooei, A. R., \& Birjandinejad, A. (2015). Validity and Reliability of the Persian Version of Shortened Disabilities of the Arm , Shoulder and Hand Questionnaire ( Quick - DASH ). International Journal of Preventive Medicine, 6(59), 1-5. https://doi.org/10.4103/20087802.160336

Feuerstein, M., Miller, V. L., Burrell, L. M., \& Berger, R. (1998). Occupational upper extremity disorders in the federal workforce. Prevalence, healthcare expenditures and patterns of work disability. Journal of Occupational and Environmental Medicine, 40(6), 546-555.

Graham, B. (2008). The value added by electrodiagnostic testing in the diagnosis of carpal tunnel syndrome. Bone Joint Surgery Am, 90, $2587-2593$.

Greenslade, J. R., Mehta, R. L., Belward, P., \& Warwick, D. J. (2004). Dash and boston questionnaire assessment of carpal tunnel syndrome outcome: What is the responsiveness of an outcome questionnaire? Journal of Hand Surgery, 29 B(2), 159-164. https://doi.org/10.1016/j.jhsb.2003.10.010

Hall, B., Lee, H. C., Fitzgerald, H., Byrne, B., Barton, A., \& Lee, A. H. (2013). Investigating the effectiveness of full-time wrist splinting and education in the treatment of carpal tunnel syndrome: a randomized controlled trial. The American Journal of Occupational Therapy : Official Publication of the American Occupational Therapy Association, 67(4), 448-459. https://doi.org/10.5014/ajot.2013.006031

Hamzeh, H. H., \& Alworikat, N. A. (2019). Cross cultural adaptation, reliability and construct validity of the Boston Carpal Tunnel Questionnaire in standard Arabic language Cross cultural adaptation , reliability and construct validity of the Boston Carpal Tunnel Questionnaire in standard Arabi. Disability and Rehabilitation, 1-6. https://doi.org/10.1080/09638288.2019.1629651

Hassankhani, G. G., Moradi, A., Birjandinejad, A., Vahedi, E., Kachonei, A., \& Ebrahimzadeh, M. H. (2018). Translation and Validation of the Persian Version the Boston Carpal Tunnel Syndrome Questionnaire. Archives of Bone and Joint Surgery, 71(1), 71-77.

Hermiz, S. J., \& Kallianen, L. K. (2017). Evidence-Based Medicine : Current Evidence in the Diagnosis and Management of Carpal Tunnel Syndrome. Plastic Reconstructive Surgery, 140(1), 120-129. https://doi.org/10.1097/PRS.0000000000003477

Hobby, J., Watts, C., \& Elliott, D. (2005). Validity and responsiveness of the Patient Evaluation Measure as an outcome measure for carpal tunnel syndrome. J Hand Surg $\mathrm{Br}, 30,350-354$.

Hopkins, W. G. (2000). Measures of Reliability in Sports Medicine and Science. 30(1), 1-15.

Hudak, P., Amadio, P., \& Bombardier, C. (1996). Development of an upper extremity outcome measure: the DASH (disabilities of the arm, shoulder and hand). American Journal of Industrial Medicine, 29, 602-608.

Imaeda, T., Uchiyama, S., Toh, S., Wada, T., Okinaga, S., Sawaizumi, T., ... Omokawa, S. (2007). Original article Validation of the Japanese Society for Surgery of the Hand version of the Carpal Tunnel Syndrome Instrument. Journal of Orthopaedic Science, 12, 14-21. https://doi.org/10.1007/s00776-006-1087-9

Kotsis, S., \& Chung, K. (2005). Responsiveness of the Michigan Hand Outcomes Questionnaire and the Disabilities of the Arm, Shoulder and Hand questionnaire in carpal tunnel surgery. Journal of Hand Surgery - American Volume., 30(1), 81-86.

Koziej, M., Trybus, M., Myd, A., Sa, K., Gniadek, M., Banach, M., \& Brudnicki, J. (2018). The Polish version of the Michigan Hand Outcomes Questionnaire : Crosscultural adaptation , reliability , construct validity , and measurement error. Journal of Hand Surgery, 43(2), 199-208. https://doi.org/10.1177/1753193417729579

Levine, D. W., Simmons, B. P., Koris, M. J., Daltroy, L. ., Hohl, G. G., Fossel, A. H., \& Katz, J. N. (1993). A self-administered questionnaire for the assessment of severity of symptoms and functional status in carpal tunnel syndrome. Journal of Bone and Joint Surgery, 75(11), 1585-1592.

Lue, Y., Lu, Y., Lin, G., \& Liu, Y. (2014). Validation of the Chinese version of the Boston Carpal Tunnel Questionnaire. Occupational Rehabilitation, 24(1), 139-145. Lynn, M. . (1986). Determination and quantification of content validity. Nursing Research, 35(6), 382-385.

MacDermid, J. C., \& Doherty, T. (2004). Clinical and electrodiagnostic testing of carpal tunnel syndrome: a narrative review. Journal of Orthopaedic and Sports Physical Therapy, 34, 565-588.

Meireles, S. M., Natour, J., Batista, D. A., Lopes, M., \& Skare, T. L. (2014). Cross-cultural adaptation and validation of the Michigan Hand Outcomes Questionnaire (MHQ) for Brazil: Validation study. Sao Paulo Medical Journal, 132, 339-347. 
Meyer, P., Lintingre, P., Pesquer, L., Poussange, N., \& Dallaudière, B. (2018). The Median Nerve at the Carpal Tunnel ... and Elsewhere. Journal of the Belgian Society of Radiology, 102(1), 1-11.

Mondelli, M., Giannini, F., \& Giacchi, M. (2002). Carpal tunnel syndrome incidence in a general population. Neurology, 58(2), 289-294. https://doi.org/10.1212/WNL.58.2.289

Multanen, J., Ylinen, J., Karjalainen, T., Kautiainen, H., Repo, J. P., \& Häkkinen, A. (2019). Relaibility and validity of the Finnish version of Boston Carpal Tunnel Questionnaire among surgically treated Carpal Tunnel Syndrome patients. Scandinavian Journal of Surgery, 1-8. https://doi.org/10.1177/1457496919851607

Ollivere, B. J., Logan, K., Ellahee, N., Miller-Jones, J. C., Wood, M., \& Nairn, D. S. (2009). Severity scoring in carpal tunnel syndrome helps predict the value of conservative therapy. Journal of Hand Surgery (European Volume), 34(4), 511-515.

Otero-Alvaro, A., Marin, M. T., \& Matas, J. A. (2016). Spanish validation of the Boston Carpal Tunnel Questionnaire. Med Clin (Barc), 146(6), $247-253$.

Padua, L., Coraci, D., Erra, C., Pazzaglia, C., Paolasso, I., Loreti, C., ... Hobson-Webb, L. D. (2016). Carpal tunnel syndrome: clinical features, diagnosis, and management. The Lancet Neurology, 15(12), 1273-1284. https://doi.org/10.1016/S1474-4422(16)30231-9

Park, D.-J., Kang, J.-H., Lee, J.-W., Lee, K.-E., Wen, L., Kim, T.-J., ... Lee, S.-S. (2013). Cross-Cultural Adaptation of the Korean Version of the Boston Carpal Tunnel Questionnaire: Its Clinical Evaluation in Patients with Carpal Tunnel Syndrome Following Local Corticosteroid Injection. Journal of Korean Medical Science, $28(7), 1095$. https://doi.org/10.3346/jkms.2013.28.7.1095

Rosales, R. S., Martin-Hidalgo, Y., Reboso-Morales, L., \& Atroshi, I. (2016). Reliability and construct validity of the Spanish version of the 6-item CTS symptoms scale for outcomes assessment in carpal tunnel syndrome. BMC Musculoskeletal Disorders, 17(1), 17-20. https://doi.org/10.1186/s12891-016-0963-5

Sezgin, M., Incel, N., Serhan, S., Camdeviren, H., As, I., \& Erdoğan, C. (2006). Assessment of symptom severity and functional status in patients with carpal tunnel syndrome: reliability and functionality of the Turkish version of the Boston Questionnaire. Disability Rehabilitation, 28(20), 1281-1285.

Shauver, M. J., \& Chung, K. C. (2009). The Minimal Clinically Important Difference of the Michigan Hand Outcomes Questionnaire. Journal of Hand Surgery, 34(3), 509-514. https://doi.org/10.1016/j.jhsa.2008.11.001

Sousa, V. D., \& Rojjanasrirat, W. (2011). Translation, adaptation and validation of instruments or scales for use in cross-cultural health care research: A clear and userfriendly guideline. Journal of Evaluation in Clinical Practice, 17(2), 268-274. https://doi.org/10.1111/j.1365-2753.2010.01434.x

Streiner, D., \& Norman, G. (2002). Health Measurement Scales: a practical guide to their development and use. (3rd Ed.). Oxford.: Oxford Medical Publications.

Trybus, M., Koziej, M., Belka, M., Bednarek, M., \& Banach, M. (2019). The Polish version of the Boston Carpal Tunnel Questionnaire : Associations between patientrated outcome measures and nerve conduction studies. Journal of Plastic, Reconstructive \& Aesthetic Surgery, 72(6), 924-932. https://doi.org/10.1016/j.bjps.2018.12.032

Turner, A., Kimble, F., Gulyás, K., \& Ball, J. (2010). Can the outcome of carpal tunnel release be predicted? ANZ Journal of Surgery, 80(1-2), 50-54

Waljee, J. F., Kim, H. M., Burns, P. B., \& Chung, K. C. (2011). Development of a brief, 12-item version of the Michigan Hand Questionnaire. Plastic and Reconstructive Surgery, 128(1), 208-220.

Waltz, C. F., Strickland, O. L., \& Lenz, E. R. (2010). Measurement in nursing and health research : Fourth edition. Retrieved from https://ebookcentral.proquest.com.

Werner, R. A., \& Andary, M. (2002). Carpal tunnel syndrome: Pathophysiology and clinical neurophysiology. Clinical Neurophysiology, 113(9), $1373-1381$. https://doi.org/10.1016/S1388-2457(02)00169-4

Yücel, H., \& Seyithanoğlu, H. (2015). Choosing the most efficacious scoring method for carpal tunnel syndrome. Acta Orthopaedica et Traumatologica Turcica, 49(1), 23-29. https://doi.org/10.3944/AOTT.2015.13.0162 